\title{
Efficacy, safety, and pharmacoeconomics of sivelestat sodium in the treatment of septic acute respiratory distress syndrome: a retrospective cohort study
}

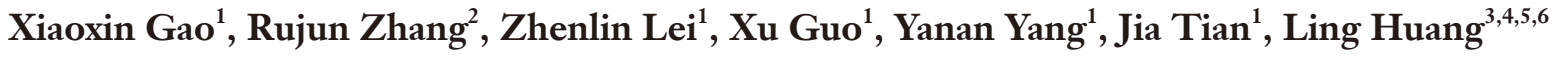 \\ ${ }^{1}$ Intensive Medical Unit, Hainan General Hospital, Hainan Affiliated Hospital of Hainan Medical University, Haikou, China; ${ }^{2}$ Department of \\ Cardiology, Hainan General Hospital; Hainan Affiliated Hospital of Hainan Medical University, Haikou, China; ${ }^{3}$ Hainan Province Key Laboratory \\ for Drug Preclinical Study of Pharmacology and Toxicology Research, Hainan Medical University, Haikou, China; ${ }^{4}$ School of Hainan Provincial \\ Drug Safety Evaluation Research Center, Hainan Medical University, Haikou, China; ${ }^{5}$ Key Laboratory of Emergency and Trauma of Ministry \\ of Education, Hainan Medical University, Haikou, China; ${ }^{6}$ Research Unit of Island Emergency Medicine, Chinese Academy of Medical Science, \\ Hainan Medical University, Haikou, China \\ Contributions: (I) Conception and design: X Gao; (II) Administrative support: J Tian, L Huang; (III) Provision of study materials or patients: X Guo; \\ (IV) Collection and assembly of data: Z Lei, Y Yang; (V) Data analysis and interpretation: R Zhang; (VI) Manuscript writing: All authors; (VII) Final \\ approval of manuscript: All authors. \\ Correspondence to: Jia Tian. Intensive Medical Unit, Hainan General Hospital; Hainan Affiliated Hospital of Hainan Medical University, 19 Xiuhua \\ Road, Haikou 570311, China. Email: 5298439@qq.com; Ling Huang. Hainan Province Key Laboratory for Drug Preclinical Study of Pharmacology \\ and Toxicology Research, Hainan Medical University, 3 Xueyuan Road, Haikou 571199, China. Email: Puer6@163.com.
}

Background: Acute respiratory distress syndrome (ARDS) is one of the most organ dysfunctions in sepsis. Although the development of therapeutic strategies such as protective mechanical ventilation technology has improved the mortality of ARDS patients, there is currently no effective drug for reducing the associated mortality. Our study aims to investigate the efficacy, safety, and pharmacoeconomics of sivelestat sodium in patients with septic ARDS, for providing the basis on clinical use of this drug.

Methods: This was a retrospective study of 140 patients with septic ARDS. Clinical information including general conditions, mechanical ventilation time, drug cost parameters, and adverse reactions. The partial pressure of $\mathrm{O}_{2}$ /fraction of inspired oxygen $\left(\mathrm{PaO}_{2} / \mathrm{FiO}_{2}\right)$, acute physiology and chronic health evaluation score (APACHE II score) and sequential organ failure assessment (SOFA score) are for assessing the severity illness. To evaluate the efficacy of sivelestat sodium on septic ARDS patients by comparing length of mechanical ventilation and intensive care unit (ICU) hospitalization, cost of hospitalization and mortality between the two groups.

Results: There were no significant differences in the incidence of organ failure, biochemical data, blood gas analysis, acute physiology and chronic health evaluation (APACHE II score), and SOFA score between the two groups on the day of admission. The $\mathrm{PaO}_{2} / \mathrm{FiO}_{2}$, APACHE II score, and SOFA score of the sivelestat sodium group were significantly better than in the control group $(\mathrm{P}<0.05)$. The length of mechanical ventilation, length of ICU hospitalization, and cost of ICU hospitalization were all lower in the sivelestat sodium group $(\mathrm{P}<0.05)$. No adverse events were reported during the study period.

Conclusions: Sivelestat sodium significantly improves the oxygenation in patients with septic ARDS, together with reducing mechanical ventilation, ICU hospitalization, and medical costs.

Keywords: Septic acute respiratory distress syndrome (septic ARDS); sivelestat sodium; safety; pharmacoeconomics

Submitted Sep 28, 2021. Accepted for publication Nov 17, 2021.

doi: 10.21037/apm-21-3164

View this article at: https://dx.doi.org/10.21037/apm-21-3164 


\section{Introduction}

Sepsis is a clinically critical, life-threatening organ dysfunction with rapid onset and progression, caused bacterial infection of the host (1-3). Statistically, the number of septic patients worldwide exceeds 19 million each year, of whom approximately 6 million die and 3 million of the survivors experience cognitive dysfunction, resulting in a serious medical and socioeconomic burden (4-6).

Due to imbalance of the inflammatory network, sepsis will lead to death through associated tissue damage and organ failure (7). Acute respiratory distress syndrome (ARDS) is one of the most organ dysfunctions in sepsis, characterized by severe hypoxemia, diffuse pulmonary infiltrates, and noncardiogenic pulmonary edema. The 2012 Berlin definition was classified the severity of ARDS into three categories: mild [200 $\mathrm{mmHg}<$ oxygenation fraction $\left(\mathrm{PaO}_{2} / \mathrm{FiO}_{2}\right) \leq 300 \mathrm{mmHg}$, positive end-expiratory pressure (PEEP) or continuous positive airway pressure (CPAP) $\left.\geq 5 \mathrm{cmH}_{2} \mathrm{O}\right]$; moderate $\left(100 \mathrm{mmHg}<\mathrm{PaO}_{2} / \mathrm{FiO}_{2}\right.$ $\leq 200 \mathrm{mmHg}, \mathrm{PEEP} \geq 5 \mathrm{cmH}_{2} \mathrm{O}$; severe $\left(\mathrm{PaO}_{2} / \mathrm{FiO}_{2}\right.$ $\left.\leq 100 \mathrm{mmHg}, \mathrm{PEEP} \geq 5 \mathrm{cmH}_{2} \mathrm{O}\right)$.

The elastase, oxygen free radicals, and various cytokines derived from neutrophils will induce the loss of vascular endothelial cells and increase vascular permeability, which plays an important role in the occurrence and development of $\operatorname{ARDS}(8,9)$. According to a systematic review, the mortality rate of ARDS patients was $43 \%$ and $44 \%$ in 2008 and 2009 , respectively $(10,11)$. It has also been reported as a major cause of death in patients with coronavirus disease 2019 (COVID-19) (12,13). Although the development of therapeutic strategies such as protective mechanical ventilation technology has improved the mortality of ARDS patients, there is currently no effective drug for reducing the associated mortality.

Sivelestat sodium is a selective neutrophil elastase inhibitor (14). Study has shown that sivelestat sodium can reduce the concentrations of interleukin-1 $\beta$ (IL-1 $\beta$ ) and tumor necrosis factor- $\alpha(\mathrm{TNF}-\alpha)$ in serum of septic animals, and reduce the infiltration and activation of inflammatory cells (15). Therefore, if it can effectively inhibit the production of inflammatory factors in the pathogenesis of sepsis, it can reduce lung tissue damage and reduce the incidence and mortality of septic ARDS. It has been shown to have a protective effect on endotoxin-induced lung injury in hamsters, guinea pigs, and sheep (16). Clinical studies have shown that sivelestat sodium shortens the duration of mechanical ventilation and stay in the intensive care unit
(ICU) and prolongs the survival time of patients with acute lung injury (ALI) $(17,18)$. However, the clinical efficacy of sivelestat sodium in patients with septic ARDS is still controversial, a few studies believe the efficacy of sivelestat sodium in patients with septic ARDS is not exactly, patients cannot benefit from it. and further studies are needed to confirm its efficacy.

In this study, we retrospectively observed the efficacy and safety of sivelestat sodium treatment in patients with septic ARDS who received mechanical ventilation, compared the medical costs and mortality of patients who received it with those who did not, and analyzed whether the use of sivelestat sodium can reduce the cost of treatment or reduce the mortality in patients with septic ARDS. This study will provide a basis for the clinical use of sivelestat sodium. We present the following article in accordance with the STROBE reporting checklist (available at https://dx.doi. org/10.21037/apm-21-3164).

\section{Methods}

\section{Patients}

In this retrospective cohort study, a total of 140 patients admitted to the Department of Intensive Medical Unit, Hainan General Hospital, Hainan Affiliated Hospital of Hainan Medical University, China, with the diagnosis of sepsis ARDS from May 2020 to December 2020 were selected. There were 86 males and 54 females, aged 24-70 years. All procedures performed in this study involving human participants were in accordance with the Declaration of Helsinki (as revised in 2013). The study was approved by Medical Ethics Committee of Hainan General Hospital (No. Med-Eth-Re[2021]248) and informed consent was taken from all the patients.

\section{Inclusion and exclusion criteria}

The inclusion criteria were as follows: (I) aged over 18 years and younger than 70 years; (II) met the Sepsis 3.0 criteria (1): confirmed or suspected infection; sequential organ failure assessment (SOFA) score $\geq 2$ points; met the ARDS Berlin criteria (19); (III) received mechanical ventilation; and were admitted to the ICU for longer than $72 \mathrm{~h}$. The patient's family members clearly understood the experimental process, volunteered to participate in this study, and signed the informed consent form.

The exclusion criteria were as follows: allergies to the 
experimental drug, chronic liver or kidney insufficiency, severe craniocerebral injury, intracranial hypertension, brain herniation, deep coma, advanced tumors, or cachexia.

\section{Grouping and patient baseline data}

Based on whether they received sivelestat sodium (Shanghai Huilun Jiangsu Pharmaceutical Co., Ltd., Shanghai, China) treatment within 7-14 days, they were divided into the control group $(n=80)$ and sivelestat sodium group $(n=60)$. There were no significant differences in gender, age, or infection type between the two groups before treatment $(\mathrm{P}>0.05)$. The organ failure and disease severity of the two groups were determined by the acute physiology and chronic health evaluation (APACHE) II score and SOFA score. The severity of ARDS was determined by partial pressure of $\mathrm{O}_{2} /$ fraction of inspired oxygen $\left(\mathrm{PaO}_{2} / \mathrm{FiO}_{2}\right)$.

\section{Treatment procedures}

Patients enrolled in this study were administered with the following treatment measures:

(I) Anti-infection treatment: based on the epidemiological characteristics of our clinical center, antibiotics were initially used empirically. At the same time, pathogenic specimens such as blood and sputum were collected to improve pathogen culture and drug susceptibility tests, and antibiotics were adjusted in a timely manner based on the pathogenic data.

(II) Respiratory function support: a PB840 ventilator (Medtronic, Dublin, Ireland) was used for mechanical ventilation. The ventilation mode was volume control and synchronous intermittent instruction. The tidal volume was $6-8 \mathrm{~mL} / \mathrm{kg}$, the inspired oxygen concentration was $40-100 \%$, and the ventilation frequency was $16-18$ times/min, positive end-expiratory pressure (PEEP) was 5$12 \mathrm{cmH}_{2} \mathrm{O}$, and the inspiratory/expiratory ratio was 1.0:2.0-1.0:2.3.

(III) Sedation and analgesia: basic analgesic sedation was performed using remifentanil and midazolam micropump with continuous pumping. The Richmond Agitation-Sedation Scale (RASS) was applied, with a target score of -2 to -3 points.

(IV) Anti-shock therapy: restrictive and individualized fluid resuscitation was given to participants with shock. For those who had difficulty correcting shock with rehydration fluids, vasoactive drugs were used to increase blood pressure. Mean arterial pressure was held at $65-70 \mathrm{mmHg}$. Urine volume was greater than $0.5 \mathrm{~mL} / \mathrm{kg} / \mathrm{h}$.

(V) Nutritional support: participants were given enteral or parenteral nutrition support. The daily energy supply was $25-30 \mathrm{kcal} / \mathrm{kg}$. Those with albumin levels lower than normal were given intravenous infusion of albumin with a target value of $30-35 \mathrm{~g} / \mathrm{L}$.

(VI) Renal function support: participants with acute kidney injury who had internal environmental disorders such as anuria, hyperkalemia, and severe metabolic acidosis were given continuous renal replacement therapy.

(VII) Other treatments included immune regulation, rehabilitation, prevention and treatment of complications, and intensive care.

(VIII) The sivelestat sodium group was given the above treatments plus intravenous infusion of sivelestat sodium (dose: $300 \mathrm{mg} / \mathrm{day}$, is determined according to the drug instructions) for a total of $7-14$ days. The control group was given the above conventional treatment.

\section{Observation indicators}

(I) General information: the site of infection, age, gender, and vital signs of the two participant groups.

(II) Efficacy parameters: indicators on the day of ICU admission and on the 7 th day: (i) inflammatory indicators: white blood cells (WBC; $\times 10^{9} / \mathrm{L}$ ), C-reactive protein (CRP; $\mathrm{mg} / \mathrm{L})$, and procalcitonin (PCT; ng/L); (ii) organ function indicators: total bilirubin $(\mu \mathrm{mol} / \mathrm{L})$, creatinine $(\mu \mathrm{mol} / \mathrm{L})$, PEEP $\left(\mathrm{cmH}_{2} \mathrm{O}\right), \mathrm{PCO}_{2}(\mathrm{mmHg})$, platelet count $\left(\times 10^{9} / \mathrm{L}\right)$; (iii) prognostic indicators: APACHE II score, SOFA score, and $\mathrm{PaO}_{2} / \mathrm{FiO}_{2}$.

(III) Adverse reactions increased: (i) blood alkaline phosphatase (U/L), alanine aminotransferase $(\mathrm{U} / \mathrm{L})$, aspartate aminotransferase $(\mathrm{U} / \mathrm{L})$, total bilirubin $(\mu \mathrm{mol} / \mathrm{L})$, urea $(\mathrm{mmol} / \mathrm{L})$, and creatinine $(\mu \mathrm{mol} / \mathrm{L})$ increased; (ii) decreased platelet $\left(\times 10^{9} / \mathrm{L}\right)$, hemoglobin $(\mathrm{g} / \mathrm{L})$, and $\mathrm{WBC}$ count $\left(\times 10^{9} / \mathrm{L}\right)$.

(IV) Drug cost parameters: (i) ICU hospitalization cost (yuan); (ii) physical examination cost (yuan); (iii) lab test cost (yuan); (iv) drug cost (yuan); (v) ICU hospitalization (days); (vi) duration of mechanical 
ventilation (h).

(V) Efficacy endpoint: the mortality rate of each group at 28 days (\%).

\section{Statistical analysis}

The software SPSS 20.0 (IBM Corp., Armonk, NY, USA) was used for data analysis. The measurement data were expressed as $\left(\bar{x}_{ \pm \mathrm{S}}\right.$, mean \pm standard deviation). One-way analysis of variance (ANOVA) was used to compare the measurement data between groups. The chi-squared test and Fisher's exact test were used to compare the count data between groups. A $\mathrm{P}$ value $<0.05$ was considered statistically significant.

\section{Results}

\section{Comparative analysis of baseline data}

As shown in Table 1, there were no significant differences between the sivelestat sodium group and the control group in terms of age, infection site, incidence of organ failure, severity of disease, biochemical data, or blood gas values.

\section{APACHE II score, SOFA score, and $\mathrm{PaO}_{2} / \mathrm{FiO}_{2}$}

Table 2 shows that the APACHE II score (sivelestat sodium group: 9.18 \pm 1.20 ; control group: $13.07 \pm 1.55$; $\mathrm{P}<0.05$ ), SOFA score (sivelestat sodium group: $1.73 \pm 1$.60; control group: 4.76 $\pm 1.97 ; \mathrm{P}<0.05$ ) and $\mathrm{PaO}_{2} / \mathrm{FiO}_{2}$ (sivelestat sodium group: $257.4 \pm 31.44$; control group: $220.30 \pm 31.49$; $\mathrm{P}<0.05$ ) were significantly different between the two groups after 7 days of treatment.

\section{Mortality and cost of patients in ICU}

During ICU hospitalization, there was no difference in mortality between the two groups (sivelestat sodium group: $5 \%$; control group: $7.5 \%, \mathrm{P}>0.05$ ) (Table 3). The ICU hospitalization cost (sivelestat sodium group: 279,218.35 $\pm 64,361.99$; control group: $308,190.67 \pm 98,132.87$, $\mathrm{P}<0.05$ ), physical examination cost (sivelestat sodium group: 889.71 \pm 122.82 ; control group: $1,180.13 \pm 1,036.95, \mathrm{P}<0.05$ ), lab test cost (sivelestat sodium group: 10,383.61 $\pm 1,364.59$; control group: $11,818.82 \pm 2,674.00, \mathrm{P}<0.05)$, length of ICU stay (sivelestat sodium group: $21.40 \pm 3.48$; control group: $25.96 \pm 6.82, \mathrm{P}<0.05)$, and duration of mechanical ventilation (sivelestat sodium group: $243.60 \pm 40.92$; control group:
$295.98 \pm 82.63, \mathrm{P}<0.05)$ were all significantly lower in the sivelestat sodium group than the control group (Table 4).

\section{Adverse events}

During the treatment, no adverse reactions were observed in any participant.

\section{Discussion}

The typical feature of sepsis is cytokine-mediated excessive inflammation (20), or cytokine storm, which can lead to clinical manifestations such as fever, shock, altered mental status, and organ dysfunction (21). Changes in the inflammatory response, coagulation, and cell death pathways induced by sepsis may lead to ALI (22). During ALI, increased alveolar epithelial microvascular permeability eventually leads to ARDS $(23,24)$. The main clinical manifestations of ARDS are a high level of pulmonary interstitial and alveolar infiltration of neutrophils, causing pulmonary interstitial and alveolar edema, congestion, alveolar hyaline membrane formation, and alveolar atrophy, resulting in an imbalance in pulmonary ventilation and the blood flow ratio, leading to refractory hypoxemia. Many recent studies have found that the elastase released by neutrophils is involved in the degradation of the main components of the extracellular matrix, such as elastin, type IV collagen, and proteoglycan, a process that is closely related to lung injury. Among the treatment strategies for ARDS, low-tidal-volume ventilation has been shown to be effective in reducing the mortality of ALI/ARDS patients. However, prolonged mechanical ventilation increases the risk of ventilator-associated pneumonia and ventilatorassociated lung injury, and there are no effective drugs that have a beneficial effect on the prognosis of patients with ARDS.

Sivelestat sodium is a selective neutrophil elastase inhibitor. It reduces pulmonary hemorrhage and exudation and reduces pulmonary edema mainly by inhibiting neutrophil aggregation, adhesion, and infiltration; it suppresses inflammatory responses and improves the symptoms of lung injury by inhibiting the release of proinflammatory factors such as interleukin-8 (IL-8) and tumor necrosis factor- $\alpha$ (TNF- $\alpha)(25,26)$. At present, sivelestat sodium has been widely used in clinic, mainly for patients with ALI/ARDS. Tsuboko et al. (27) showed that sivelestat sodium shortened mechanical ventilation and improved pulmonary function and multiple-organ 
Table 1 The basic condition of patients on the day of ICU admission

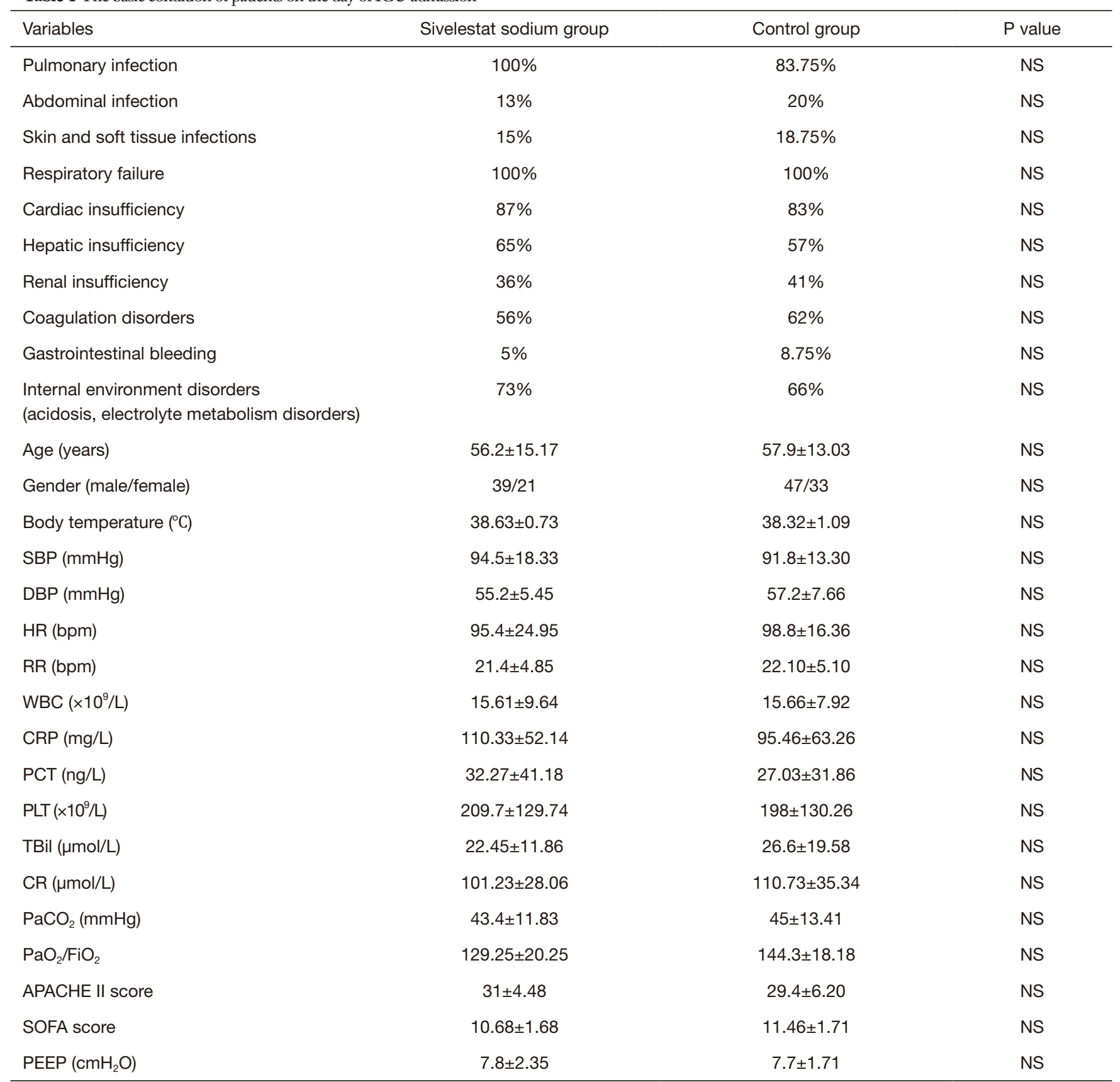

Data are presented as percentage (\%) or mean \pm standard deviation. SBP, systolic blood pressure; DBP, diastolic blood pressure; HR, heart rate; bpm, beats per minute; RR, respiratory rate; WBC, white blood cell count; CRP, C-reactive protein; PCT, procalcitonin; PLT, platelet count; TBil, total bilirubin; $\mathrm{CR}$, creatinine; $\mathrm{PaCO}_{2}$, arterial partial pressure of carbon dioxide; $\mathrm{PaO}_{2} / \mathrm{FiO} \mathrm{O}_{2}$, partial pressure of $\mathrm{O}_{2}$ /fraction of inspired oxygen; APACHE II, acute physiology and chronic health evaluation; SOFA, sequential organ failure assessment; PEEP, positive end-expiratory pressure; NS, not significant. 
Table 2 Statistical data of patients in the two groups after 7 days of treatment

\begin{tabular}{|c|c|c|c|}
\hline Variables & Sivelestat sodium group & Control group & $P$ value \\
\hline $\mathrm{SBP}(\mathrm{mmHg})$ & $110.45 \pm 10.97$ & $114.80 \pm 11.98$ & NS \\
\hline $\mathrm{DBP}(\mathrm{mmHg})$ & $54.1 \pm 8.65$ & $57.51 \pm 8.28$ & NS \\
\hline HR (bpm) & $73.78 \pm 11.25$ & $76.36 \pm 10.52$ & NS \\
\hline WBC $\left(\times 10^{9} / L\right)$ & $7.40 \pm 1.99$ & $7.00 \pm 1.74$ & NS \\
\hline $\mathrm{CRP}(\mathrm{mg} / \mathrm{L})$ & $33.15 \pm 15.28$ & $34.03 \pm 12.35$ & NS \\
\hline PCT (ng/L) & $2.36 \pm 2.23$ & $2.02 \pm 1.17$ & NS \\
\hline $\operatorname{PLT}\left(\times 10^{9} / \mathrm{L}\right)$ & $175.57 \pm 49.28$ & $177.63 \pm 46.41$ & NS \\
\hline $\mathrm{PaCO}_{2}(\mathrm{mmHg})$ & $41.42 .6 \pm 6.09$ & $40.40 \pm 6.14$ & NS \\
\hline $\mathrm{PaO}_{2} / \mathrm{FiO}_{2}$ & $257.4 \pm 31.44$ & $220.30 \pm 31.49$ & $<0.05$ \\
\hline APACHE II score & $9.18 \pm 1.20$ & $13.07 \pm 1.55$ & $<0.05$ \\
\hline SOFA score & $1.73 \pm 1.60$ & $4.76 \pm 1.97$ & $<0.05$ \\
\hline PEEP $\left(\mathrm{cmH}_{2} \mathrm{O}\right)$ & $5.11 \pm 0.32$ & $5.28 \pm 0.45$ & NS \\
\hline
\end{tabular}

Data are presented as mean \pm standard deviation. SBP, systolic blood pressure; DBP, diastolic blood pressure; HR, heart rate; bpm, beats per minute; RR, respiratory rate; WBC, white blood cell count; CRP, C-reactive protein; PCT, procalcitonin; PLT, platelet count; TBil, total bilirubin; $\mathrm{CR}$, creatinine; $\mathrm{PaCO}_{2}$, arterial partial pressure of carbon dioxide; $\mathrm{PaO}_{2} / \mathrm{FiO}_{2}$, partial pressure of $\mathrm{O}_{2} /$ fraction of inspired oxygen; APACHE II, acute physiology and chronic health evaluation score; SOFA, sequential organ failure assessment; PEEP, positive endexpiratory pressure; NS, not significant.

Table 3 Efficacy endpoints (28 days)

\begin{tabular}{lccc}
\hline Variables & Sivelestat sodium group & Control group & P value \\
\hline Number of deaths & 3 & 6 & NS \\
Mortality (\%) & 5 & 7.5 & NS \\
\hline
\end{tabular}

NS, not significant.

Table 4 Cost parameters

\begin{tabular}{lccc}
\hline Variables & Sivelestat sodium group & Control group & P value \\
\hline ICU hospitalization costs (yuan) & $279,218.35 \pm 64,361.99$ & $308,190.67 \pm 98,132.87$ & $<0.05$ \\
Physical examination cost (yuan) & $889.71 \pm 122.82$ & $1,180.13 \pm 1,036.95$ \\
Lab test cost (yuan) & $10,383.61 \pm 1,364.59$ & $11,818.82 \pm 2,674.00$ & $25.96 \pm 6.82$ \\
Length of ICU hospitalization (days) & $21.40 \pm 3.48$ & $295.98 \pm 82.63$ & $<0.05$ \\
Duration of mechanical ventilation time $(\mathrm{h})$ & $243.60 \pm 40.92$ & $<0.05<$ \\
\hline
\end{tabular}

Data are presented as mean \pm standard deviation. ICU, intensive care unit; NS, not significant. 
dysfunction scores in postoperative abdominal sepsis patients. Some scholars have found that sivelestat sodium greatly reduced the incidence of ALI in patients with esophageal cancer. A multicenter clinical study in Japan showed that patients who received sivelestat sodium treatment could be weaned off mechanical ventilation earlier, and their 180-day survival rate was significantly increased (17).

In this study, we found sivelestat sodium could improve the oxygenation of septic ARDS patients, shortened their mechanical ventilation and ICU stay, and reduced their medical costs. A cost-analysis study showed that the surgery costs in the sivelestat group were significantly lower compared with the control group, but there were no significant differences in the hospitalization, medication and total costs. Therefore, using sivelestat sodium can not increase additional medical costs. In addition, no adverse reactions were observed in participants older than 60 years, indicating that sivelestat sodium is also suitable for the elderly population. There was no significant difference in mortality between the two groups, which may be due to the small sample and the short efficacy endpoint, larger sample, multi-centre trials are needed. This study is limited by its retrospective nature. Further studies should be conducted to confirm the efficacy of the early use of sivelestat sodium for ARDS, especially among Asian populations.

\section{Conclusions}

There was no significant difference in the mortality of the two participant groups. Sivelestat sodium can improve the oxygenation of patients with septic ARDS, shorten their mechanical ventilation and ICU stay, and reduce the medical cost of hospitalization in ICU.

\section{Acknowledgments}

Funding: This study was funded by grants from the General Project of Natural Science Foundation of Hainan Province (820MS138), Medical and Health Research Projects in Hainan Province (1801320249A2002), National Natural Science Foundation of China (81760674), and the National Natural Science Foundation of China (82060678).

\section{Footnote}

Reporting Checklist: The authors have completed the STROBE reporting checklist. Available at https://dx.doi. org/10.21037/apm-21-3164

Data Sharing Statement: Available at https://dx.doi. org/10.21037/apm-21-3164

Conflicts of Interest: All authors have completed the ICMJE uniform disclosure form (available at https://dx.doi. org/10.21037/apm-21-3164). The authors have no conflicts of interest to declare.

Ethical Statement: The authors are accountable for all aspects of the work in ensuring that questions related to the accuracy or integrity of any part of the work are appropriately investigated and resolved. All procedures performed in this study involving human participants were in accordance with the Declaration of Helsinki (as revised in 2013). The study was approved by Medical Ethics Committee of Hainan General Hospital (No. Med-Eth$\operatorname{Re}[2021] 248)$ and informed consent was taken from all the patients.

Open Access Statement: This is an Open Access article distributed in accordance with the Creative Commons Attribution-NonCommercial-NoDerivs 4.0 International License (CC BY-NC-ND 4.0), which permits the noncommercial replication and distribution of the article with the strict proviso that no changes or edits are made and the original work is properly cited (including links to both the formal publication through the relevant DOI and the license). See: https://creativecommons.org/licenses/by-nc-nd/4.0/.

\section{References}

1. Singer M, Deutschman CS, Seymour CW, et al. The Third International Consensus Definitions for Sepsis and Septic Shock (Sepsis-3). JAMA 2016;315:801-10.

2. Shankar-Hari M, Phillips GS, Levy ML, et al. Developing a New Definition and Assessing New Clinical Criteria for Septic Shock: For the Third International Consensus Definitions for Sepsis and Septic Shock (Sepsis-3). JAMA 2016;315:775-87.

3. Seymour CW, Liu VX, Iwashyna TJ, et al. Assessment of Clinical Criteria for Sepsis: For the Third International Consensus Definitions for Sepsis and Septic Shock (Sepsis-3). JAMA 2016;315:762-74.

4. Perner A, Cecconi M, Cronhjort M, et al. Expert statement for the management of hypovolemia in sepsis. Intensive Care Med 2018;44:791-8. 
5. Prescott HC, Angus DC. Postsepsis Morbidity. JAMA 2018;319:91.

6. Reinhart K, Daniels R, Kissoon N, et al. Recognizing Sepsis as a Global Health Priority - A WHO Resolution. N Engl J Med 2017;377:414-7.

7. Aziz M, Jacob A, Yang WL, et al. Current trends in inflammatory and immunomodulatory mediators in sepsis. J Leukoc Biol 2013;93:329-42.

8. Ware LB, Matthay MA. The acute respiratory distress syndrome. N Engl J Med 2000;342:1334-49.

9. Zeiher BG, Artigas A, Vincent JL, et al. Neutrophil elastase inhibition in acute lung injury: results of the STRIVE study. Crit Care Med 2004;32:1695-702.

10. Zambon M, Vincent JL. Mortality rates for patients with acute lung injury/ARDS have decreased over time. Chest 2008;133:1120-7.

11. Phua J, Badia JR, Adhikari NK, et al. Has mortality from acute respiratory distress syndrome decreased over time?: A systematic review. Am J Respir Crit Care Med 2009;179:220-7.

12. Yang $\mathrm{X}, \mathrm{Yu} \mathrm{Y}, \mathrm{Xu} \mathrm{J}$, et al. Clinical course and outcomes of critically ill patients with SARS-CoV-2 pneumonia in Wuhan, China: a single-centered, retrospective, observational study. Lancet Respir Med 2020;8:475-81.

13. Cao W, Fang Z, Hou G, et al. The psychological impact of the COVID-19 epidemic on college students in China. Psychiatry Res 2020;287:112934.

14. Miyoshi S, Hamada H, Ito R, et al. Usefulness of a selective neutrophil elastase inhibitor, sivelestat, in acute lung injury patients with sepsis. Drug Des Devel Ther 2013;7:305-16.

15. Suda K, Takeuchi H, Hagiwara T, et al. Neutrophil elastase inhibitor improves survival of rats with clinically relevant sepsis. Shock 2010;33:526-31.

16. Iba T, Kidokoro A, Fukunaga M, et al. Pretreatment of sivelestat sodium hydrate improves the lung microcirculation and alveolar damage in lipopolysaccharide-induced acute lung inflammation in hamsters. Shock 2006;26:95-8.

17. Aikawa N, Ishizaka A, Hirasawa H, et al. Reevaluation of the efficacy and safety of the neutrophil elastase inhibitor,
Sivelestat, for the treatment of acute lung injury associated with systemic inflammatory response syndrome; a phase IV study. Pulm Pharmacol Ther 2011;24:549-54.

18. Tamakuma S, Ogawa M, Aikawa N, et al. Relationship between neutrophil elastase and acute lung injury in humans. Pulm Pharmacol Ther 2004;17:271-9.

19. ARDS Definition Task Force; Ranieri VM, Rubenfeld GD, et al. Acute respiratory distress syndrome: the Berlin Definition. JAMA 2012;307:2526-33.

20. Boomer JS, To K, Chang KC, et al. Immunosuppression in patients who die of sepsis and multiple organ failure. JAMA 2011;306:2594-605.

21. Angus DC. Management of sepsis: a 47-year-old woman with an indwelling intravenous catheter and sepsis. JAMA 2011;305:1469-77.

22. Herrero R, Martin-Loeches I, Artigas A. The Complex Interaction between Sepsis and Lung Injury. In book: Annual Update in Intensive Care and Emergency Medicine 2012 (pp.149-159). DOI:10.1007/978-3-64225716-2_15.

23. Patel BV, Wilson MR, O'Dea KP, et al. TNF-induced death signaling triggers alveolar epithelial dysfunction in acute lung injury. J Immunol 2013;190:4274-82.

24. Miyoshi K, Yanagi S, Kawahara K, et al. Epithelial Pten controls acute lung injury and fibrosis by regulating alveolar epithelial cell integrity. Am J Respir Crit Care Med 2013;187:262-75.

25. Lee JM, Yeo CD, Lee HY, et al. Inhibition of neutrophil elastase contributes to attenuation of lipopolysaccharideinduced acute lung injury during neutropenia recovery in mice. J Anesth 2017;31:397-404.

26. Xiao XG, Zu HG, Li QG, et al. Sivelestat sodium hydrate attenuates acute lung injury by decreasing systemic inflammation in a rat model of severe burns. Eur Rev Med Pharmacol Sci 2016;20:528-36.

27. Tsuboko Y, Takeda S, Mii S, et al. Clinical evaluation of sivelestat for acute lung injury/acute respiratory distress syndrome following surgery for abdominal sepsis. Drug Des Devel Ther 2012;6:273-8.

(English Language Editor: J. Jones)
Cite this article as: Gao X, Zhang R, Lei Z, Guo X, Yang Y, Tian J, Huang L. Efficacy, safety, and pharmacoeconomics of sivelestat sodium in the treatment of septic acute respiratory distress syndrome: a retrospective cohort study. Ann Palliat Med 2021;10(11):11910-11917. doi: 10.21037/apm-21-3164 